doi: $10.3935 /$ rsp.v25i3.1522

\section{ESTIMATING LABOUR MARKET SLACK IN THE EUROPEAN UNION}

\section{John Hurley and Valentina Patrini}

Dublin: Eurofound, 2017., 56 str.

In the social policy and political discussions sufficient attention is usually oriented to the number of unemployed persons, while some other important issues related to the labour market are hidden or neglected. One of these is the labour market slack. That is the difference between the volume of work desired by workers and the actually available volume of work. The unemployment rate, as a usual indicator of the labour market situation, does not take account of inactivity that is often a bigger problem than open unemployment. John Hurley and Valentina Patrini from Eurofound prepared a very useful book about the phenomenon of the labour market slack entitled Estimating labour market slack in the European Union1. This publication is a part of the Project Unemployment, underemployment and inactivity: Estimating labour market slack in the European Union.

In comparison with other developed countries (USA and Japan), the unemployment rate in the EU is significantly higher and still well above its level before the global financial crisis. It can be a surprise but a large majority of the working age population (15-64 years-old) without a job are not unemployed, but are inactive. Unemployed people do not have a job, but actively seek work and are available for work. On the other side, an inactive person is neither employed nor unemployed and does not seek employment. In the European Union during 2015, more than one third of the non-employed working-age population were groups of unemployed and inactive persons. Out of these, around one in five persons was unemployed, while the remaining four were inactive. Using the EU Labour Force Survey data, the authors clarify a broader measure of labour slack in the EU. It covers the unemployed, but also involuntary part-time and inactive people with some labour market attachment.

In the Introduction, the authors explain the main motivations for the Project: a relatively high share of labour inactivity, increasing fragmentation nature of the presentday labour market and the wish to analyse the role of anticipated wage. One possibility to avoid inadequacies of the unemployment rate as a performance indicator of the labour market is to use the employment rate instead. Such approach enables a more comprehensive view of the labour market, because it includes the total inactive population. However, not even the employment rate is perfect because it does not include particular dimensions of labour market slack. For example, it does not distinguish between the labour input of someone working a very short period (for example, 1 or 2 hours per week) and someone working full time (40 hours). The EU-Labour Force Survey (LFS) provides various possibilities to distinguish between persons working very short hours, including those that would like to work longer hours. The starting point of the survey was to examine in more detail various categories of joblessness and underemployment based on microdata

\footnotetext{
1 The publication is available on: https:/www.eurofound.europa.eu/sites/default/files/ef_publication/ field ef document/ef1711en.pdf
} 
from the EU-LFS. The idea was to analyse how these topics evolve, how they are composed and what factors may contribute to their changes.

Chapter 1 defines labour market slack in more detail. It is the situation on the labour market when there are more workers willing to work in comparison with the available number of hours provided by existing jobs or in other words the insufficiency of available work. As persons cannot satisfy their wish to work, they get frustrated and stay involuntarily jobless. Another possibility is that they have fewer working hours than they would like to have. In such circumstances - when there are more workers than available working hours - employers have a more powerful position and they will try to lower the workers' remuneration. Labour market slack is a part of the broader term labour underutilisation, which also includes low earnings and skill mismatch. These other terms are not included in this publication. An assessment of the labour slack is also an important element for defining the output gap and for decision making regarding economic policy, such as monetary interventions. The authors underline that unemployment and joblessness are not only a waste of resources, but also have adverse consequences on unemployed persons. To be out of the world of work leads to increased risk of poverty and homelessness, bad familial relations and serious health problems. The text also explains the characteristics of employment and underemployment on one side and the inactivity on the other. Inactive people occupy a grey space between entire inactivity and the active labour market. This group also includes discouraged workers, people who want to work but have withdrawn from the labour market because they do not believe that there are available jobs suitable for them.
Chapter 2 explains how to measure the labour market slack and other forms of underemployment. There are various proxy measures of mentioned phenomena based on macroeconomic data, such as decreased numbers of advertised vacancies or a declining ratio of vacancies to unemployed people; the problems faced by employers in filling vacant posts; lowering the real wage levels; and other forms of visible underemployment that are recorded using LFS. It is reasonable to deem these approaches as part of a scale with many grey spaces between working statuses of individual person. The EU-LFS, for example, contains a number of questions needed to collect the data on potential additional labour force. The US Bureau of Labor Statistics proposes six different measures of labour market underutilisation. Three of them refer to people unemployed for 15 weeks or longer as a percentage of the civilian labour force; people who lost jobs and who completed temporary jobs as a percentage of the civilian labour force and the total unemployed as a percentage of the civilian labour force. The other three measures are somewhere broader, as they take into account additional groups as follows: marginally attached individuals who are not in the labour force, but are willing and are available for work; discouraged workers and people involuntary employed part-time. There are some other measures used for the estimation of non-employment that have developed to address apparent weaknesses of the unemployment rate as a measure of labour market performance. They enable incorporation of supplementary forms of marginally attached workers and those that are underemployed.

An estimation of labour market slack in the EU is presented in the Chapter 3. In the EU in 2015 there were almost 23 million 
unemployed people and further 21 million people who were underemployed or in the potential additional labour force. These workers wished to work longer hours and were employed only on part-time work in the absence of a position offering them their desired working hours. A further category of interest are persons who are not currently seeking employment and are not available for employment in the next two weeks, but would still like to work. In 2015, there were over six million people in this category. One should not neglect almost one million of workers on lay-off or a temporary employer-initiated break from job, where the employment relationship has been suspended but not completely broken. Thus, we can conclude that the number of persons with some attachment to the labour market is huge, almost two times bigger that the total number of the unemployed population. One of the most outstanding events in European labour markets during a few last decades is an increased share of part-time employment. Around one fifth of all jobs in the EU28 are part-time in comparison to $16 \%$ in 1996 . The recent increase in the share of part-time jobs was a consequence of growing levels of part-time work and contracting number of full-time work. A particularly visible feature of part-time work is the widespread and amplified use of very short part-time working hours (less than 10 hours per week) whose share in the EU increased from $3.4 \%$ of all employees in 1996 to $4.6 \%$ in 2015 . While the female labour force accounts for the majority of part-time work with very short hours, the share of the male has grown relatively faster since 1996. Thus, the mentioned share increased from $1.5 \%$ to $2.8 \%$ for all male workers in comparison with females' share which increased from $6.1 \%$ to $6.6 \%$ of all women that work. There is an inverse relationship between the share of part-time work in the total employment and involuntary form of this work. The EU members that have a higher share of part-time work (like Austria, Germany, Denmark, Sweden, and the UK) have a lower percentage of involuntary part-time work. On the other side, Croatia is between the countries with a very small share of part-time work - less than $5 \%$ of total employment, but with the highest share of involuntary part-time - almost 50\%. Together with Poland and Sweden, Croatia is in the group of countries where the share of part-time work decreased during the economic crisis. From all presented information, it seems that involuntary part-time work is linked with poor labour market performance and with other indicators of the labour slack, such as the high unemployment rate. Younger workers are more likely to have involuntary part-time employment what presents an additional problem to the well-known unfavourable situation of the young people on the labour market. Regarding other relations, the authors stress that there is a weak correlation between general labour market indicators, like the employment or unemployment rate at the national level, and the share of those who are inactive, not seeking work but available and willing to work. The most important reason why inactive people who are willing and available to work do not seek work is their strong belief that no work is available.

Chapter 4 takes a different approach and tries to identify changes in labour market participation where the existence of the labour market slack may be caused by variations in trends of labour market participation. The authors analyse employment and participation rates by age and gender, as well as changes in the reasons that caused the inactivity. There is an obvious increase in the levels of self-reported incapacity or disability. In many developed countries 
there is an outstanding long-term decline in the participation and employment rates for prime-age men (aged 25 to 54). The authors describe some of these longerterm trends and give possible explanatory factors related to the applicable national policy, institutional or demographic determinants on the labour market. As mentioned, such trends often result from disability and discouragement. Regarding the age, in the EU15 in the period between 1998 and 2015, younger workers (aged 15-24) were the only group that had negative employment change in both gender groups. This is caused by increased participation of this group in education and training. Such increase in good inactivity can have positive long-term consequences for the enhancement of human capital. However, longer stay in education can be attributed to the economic crisis because young people do not believe that they will find adequate job and in that way create another form of labour slack. Regarding the gender, the participation rate for men in the period between 1998 and 2015 decreased by 1.3 percentage points, while for women it increased by 2.7 percentage points. Although the gender employment gaps in 2015 are closing, they are still prominent (11.6 percentage points) between female (72.2\%) and male $(83.8 \%)$ in the age group 25-54. Additional interesting feature is the strong increase in employment rates of older female workers (55-64 years). That is the result of demographic ageing and longer stay in the labour force for persons in this age group. This means that the previous trends towards shorter working lives and early retirement are now mostly reversed. The factors that may have contributed to the decrease in the prime-age male employment and activity rates include demographic characteristics (education, family and migration status), demand-related factors (em- ployment decline in sectors predominantly employing men), supply-driven factors (men decide not to work in a current set of labour market conditions) and institutional factors. Even though the educational attainment has become an even more important factor for labour market participation and employment rates, it is surprising that the actual rates of employment and participation of people with tertiary-level educational attainment in the EU have been stable or somewhat declining since 2002. However, lowered labour market participation is strongly pronounced by those that have not completed tertiary education. EU-LFS data show that the main reason for primeage male inactivity is an illness or disability for work, what can be partially explained by relatively generous disability benefits and/or extensive public support. A much higher incidence of labour inactivity caused by illness or disability is recorded for men than for women ( $41 \%$ versus $17 \%)$. The situation varies, so in the countries with favourable labour market conditions the discouragement element is not present, while in the countries with adverse labour market conditions its impact is significant. A decline in labour demand for lowerskilled workers has disproportionately impacted on men and on predominantly maleemploying sectors (like manufacturing and construction). Alternative jobs in service sector for those male workers previously employed in manufacturing and construction are less paid what probably also motivates many men against re-entering into the labour market.

The short conclusion recaps the most important conclusion from the research. Due to increasing participation rates, particularly among female and older persons, today there are more people of working age in the labour market. There is an increase in the number of inactive people who are 
willing to work and people who are involuntary working part-time. While the unemployment rate in the EU was $9.5 \%$ in 2017 , the labour slack rate was $15 \%$ and it was higher in 2015 than in 2008. Next to the population of unemployed job-seekers, two largest labour slack categories were people working involuntarily as part-timers (almost 10 million in 2015) and those people who were available and wishing to work, but who were inactive because there were not seeking work (almost 9 million in 2015). Involuntary part-timers were most likely to work in basic or lower-level service occupations and they were also more likely to be women. The second large category of labour slack is that of inactive discouraged people who are not seeking work. They strongly believe that there is no available work or that possible jobs provide low salaries.

The identified categories of labour market slack represent a grey zone between inactivity and open unemployment and they have many similarities with the jobseeker populations. Despite a pronounced increase in older worker participation, there is still a sizeable potential workforce remaining among older persons willing to work, but discouraged from seeking a job. In that way, various measures and public information campaigns can be of crucial importance for their re-entrance into the labour market. This is particularly important in the current circumstances of demographic ageing and a shortage of the labour force, but can also be a valuable method for the reduction of social welfare and pension expenditures. Finally, work is the best medicine against loneliness and health problems. Due to the changes on the labour market - the widespread presence of various marginal and non-standard employments, as well as with the increasing share of involuntary part-time work - the future will probably bring further significant slacks. In that way, the publication Estimating labour market slack in the European Union by Hurley and Patrini is an important beginning of new researches of the labour market.

Predrag Bejaković

Institute of Public Finance, Zagreb 